\title{
Knowledge and Attitude towards Stroke Risk Factors, Warning Symptoms and Treatment in an Iranian Population
}

\author{
Afshin Borhani Haghighi $^{a} \quad$ Ali Asghar Karimi $^{\text {b }} \quad$ Ali Amiri $^{\text {b }}$ \\ Fariborz Ghaffarpasand ${ }^{b}$ \\ ${ }^{a}$ Transgenic Technology Research Center and Department of Neurology, Shiraz University of Medical Sciences,

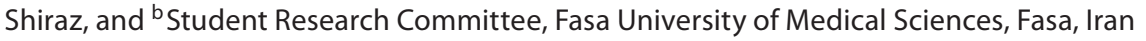

\section{Key Words}

Stroke $\cdot$ Knowledge $\cdot$ Risk factors $\cdot$ Iran

\begin{abstract}
Objectives: To assess the baseline knowledge regarding stroke risk factors, symptoms, treatment and information resources in an Iranian urban population. Subjects and Methods: A community-based face-to-face interview survey was conducted in the Shiraz urban area in Iran. A total of 385 potential participants between the ages of 15 and 83 years were randomly selected from people referred to Motahari Clinic, Shiraz University of Medical Sciences, Shiraz. All the participants answered the 63 questions about different aspects of stroke. SPSS software version 15 was used to analyze the data. Results: The 385 participants completed the face-to-face interview. The most common risk factors for stroke identified by respondents were hypertension (342; 88.8\%) and smoking $(338 ; 87.8 \%)$. The most common warning signs of stroke were abdominal pain $(370 ; 96.1 \%)$ and chest pain $(338 ; 88.7 \%)$. Conclusion: This study shows that the knowledge of and attitude towards stroke risk factors in the general population of Shiraz are adequate. By using the public media and school education, it is possible to promote the level of the population's knowledge of and attitude towards stroke.
\end{abstract}

Copyright $\odot 2010$ S. Karger AG, Basel

\section{KARGER}

Fax +4161306 1234

E-Mail karger@karger.ch

www.karger.com (c) 2010 S. Karger AG, Basel

1011-7571/10/0196-0468\$26.00/0

Accessible online at:

www.karger.com/mpp

\section{Introduction}

Currently, stroke represents a serious problem in public health $[1,2]$. Stroke is the second most common cause of death worldwide and a significant cause of chronic disability [3]. Contributing to this is the aging of the population, lack of knowledge regarding cerebrovascular disease and increased frequency of the risk factors, mainly hypertension $[4,5]$. The main clinical manifestations are paralysis, dysarthria, aphasia, vision alterations, headache, numbness, dizziness or weakness $[4,5]$. The public's knowledge of these warning signs is very important. Quick identification of these signs means a more efficient medical attendance within the windows of therapeutic opportunities. Rapid reperfusion with thrombolytic agents within $3 \mathrm{~h}$ of the onset of symptoms has been shown to be beneficial as such and to reduce morbidity and mortality [2, 6]. Rapid admission to a hospital after the onset of stroke depends partially on the level of knowledge of stroke [7]. Otherwise, patients with stroke may fail to gain from the benefits of acute treatments such as acute thrombolysis, because of the narrow therapeutic window [8]. It has been reported that knowledge about the risk factors of stroke can help prevent stroke in the first place [9]. Delay in presentation to the emergency department outside of the various treatment time windows 
for reperfusion therapy remains a significant barrier in the treatment of acute stroke [10].

Population-based studies have shown that there is a lack of knowledge about established stroke risk factors and warning signs in the USA [9, 11-13], Australia [14], South Korea [15], Canada [16], Brazil [17], Oman [18], India [19] and Turkey [20]. In Iran, the public's level of knowledge of symptoms and risk factors for stroke has not been studied so far. Thus, it is of great clinical and epidemiological interest to know the magnitude of the problem so that strategies can be adopted to minimize the unfavorable effects of stroke.

The aim of the present study was to assess the baseline knowledge of and attitude towards warning symptoms of stroke, impending risk factors, treatment, availability of sources of information and the perceived risk of stroke among people attending the Neurology Department of Motahari Clinic of Shiraz.

\section{Subjects and Methods}

The present study is based on a face-to-face interview survey in the Department of Neurology, Motahari Clinic, Shiraz University of Medical Sciences, Shiraz, Iran, which was conducted between June and July 2008. The sample was randomly selected from literate people who accepted to participate in this study. Individuals $\geq 15$ years of age, who consented, were interviewed personally. The questions were asked during a face-to-face interview in Persian. The interviewer intervened only to clarify a question, if required, but did not reveal any information about warning signs and risk factors of stroke. No attempt was made to prompt the respondents by suggesting answers directly.

\section{Questionnaire}

All questions were open-ended with options for multiple responses (for the questions, see the appendix). The survey instrument was pretested using a sample of 100 people, with an access error of $1.5 \pm 8.8, \alpha=99 \%$ and $n=230$. Changes were made in the questionnaire to various terms that were used for 'stroke' in the local language Persian. This was done entirely to differentiate heart attack from stroke in the local language.

The questionnaire consisted of 69 questions: demographic information (6), knowledge (45), attitude (12) and error-correcting (6), which were modified by the authors to suit local sociocultural practices. The first section gathered demographic information consisting of age, sex and residence (urban, rural or immigrant). Education was categorized into diploma (12th standard), licentiate (16th standard), postlicentiate (18th standard) and doctoral or higher. The years of education were written by the interviewee. Income groups were classified as high with $>$ USD 1,000/month, intermediate with USD 200-1,000 and poor with USD $<200$. Sections 2 and 3 covered awareness of stroke warning symptoms, risk factors and treatment. The last section of the survey was aimed at finding out whether the respondents had any of the listed risk fac-

Knowledge of Stroke Risk Factors in Shiraz
Table 1. Demographic characteristics of the 385 respondents

\begin{tabular}{lc}
\hline Characteristics & Value \\
\hline Age, years & $35.13 \pm 12.46(15-83)$ \\
Sex & \\
$\quad$ Male & $166(43.1 \%)$ \\
Female & $219(56.9 \%)$ \\
Residence & $326(84.7 \%)$ \\
Urban & $44(11.4 \%)$ \\
Rural & $5(1.5 \%)$ \\
Immigrant & $10(2.6 \%)$ \\
Missing & \\
Years of education & $230(59.7 \%)$ \\
$\quad 12$ & $92(23.9 \%)$ \\
$13-16$ & $6(1.6 \%)$ \\
$17-19$ & $7(1.8 \%)$ \\
$\geq 20$ & \\
Income & $162(42.1 \%)$ \\
Low & $173(44.9 \%)$ \\
Moderate & $13(3.4 \%)$ \\
High &
\end{tabular}

tors for stroke. A total of 400 people aged 15 years or older were interviewed. Fifteen people were excluded from the study due to errors in filling in the forms, and thus the number of people who finished the study was 385 .

\section{Statistical Analysis}

The statistical package for the social sciences, SPSS for Windows, version 15.0 (SPSS, Chicago, Ill., USA), was used for data analysis. Data are reported as the mean \pm SD with $95 \%$ confidence interval and 5\% degree of freedom. The $\chi^{2}$ test was used to compare proportions. Pearson's correlation coefficients were used to calculate the correlation between paired data sets. A twosided $\mathrm{p}$ value $<0.05$ was considered statistically significant.

\section{Results}

The demographic characteristics of the participants are given in table 1 . Hypertension was the most cited factor followed by smoking and vascular rupture (table 2). Of the 385 participants, 344 (89.3\%) agreed that controlling blood pressure can prevent stroke, 30 (7.8\%) did not know and 11 (2.9\%) answered that it cannot prevent stroke (table 3). Of the 357 participants who answered the question on familial cases of stroke, $32.49 \%$ were related to stroke victims, while $4.2 \%$ had already had a stroke. With regard to the participants' attitude, 303 (78.7\%) and 71 (18.4\%) completely and partially agreed, respectively, that stroke patients must be treated by a neurologist (table 4 ). 
Table 2. Knowledge of the 385 respondents about stroke risk factors and warning signs

\begin{tabular}{ll}
\hline Risk factors/warning signs & Correct \\
\hline Risk factors & \\
Hypertension & $342(88.8 \%)$ \\
Smoking & $338(87.8 \%)$ \\
Vascular rupture & $307(79.7 \%)$ \\
Familial history & $246(63.9 \%)$ \\
Arrhythmia & $229(59.5 \%)$ \\
Hypercholesterolemia & $228(59.2 \%)$ \\
Obesity & $224(58.2 \%)$ \\
Myocardial infarction & $203(52.7 \%)$ \\
Thrombosis & $201(52.2 \%)$ \\
Nervousness & $156(40.5 \%)$ \\
Hypertriglyceridemia & $141(36.6 \%)$ \\
Diabetes mellitus & $120(31.2 \%)$ \\
Warning signs & \\
Abdominal pain & $370(96.1 \%)$ \\
Chest pain & $338(88.7 \%)$ \\
Dyspnea & $333(86.5 \%)$ \\
Paralysis & $292(75.8 \%)$ \\
Hemiplegia & $285(74.0 \%)$ \\
Aphasia & $244(63.4 \%)$ \\
Body pain & $236(61.3 \%)$ \\
Ataxia & $166(43.1 \%)$ \\
Urinary and fecal incontinence & $152(39.5 \%)$ \\
Vertigo & $146(37.9 \%)$ \\
Depression & $139(36.1 \%)$ \\
Cold sweat & $92(23.9 \%)$ \\
Double vision & $79(20.5 \%)$ \\
\hline & \\
\hline &
\end{tabular}

Table 3. Proportion of persons who correctly identified stroke risk factors and warning signs

\begin{tabular}{lc}
\hline $\begin{array}{l}\text { Reactions in a case of acute stroke, } \\
\text { prevention and treatment of stroke }\end{array}$ & Frequency \\
\hline Reaction & \\
$\quad$ Emergency room & $369(95.8 \%)$ \\
$\quad$ Neurologist office & $327(84.9 \%)$ \\
$\quad$ Transfer by ambulance & $290(75.4 \%)$ \\
Prevention & \\
Control of blood pressure & $344(89.4 \%)$ \\
Diet & $291(75.6 \%)$ \\
Control of diabetes & $135(35.1 \%)$ \\
No prevention & $57(14.8 \%)$ \\
Treatment & \\
Physiotherapy & $323(83.9 \%)$ \\
Surgery & $291(75.6 \%)$ \\
Medical & $117(30.4 \%)$ \\
No treatment & $27(7.0 \%)$ \\
\hline
\end{tabular}

There were no significant correlations between sex and domicile with knowledge $(\mathrm{p}=0.164, \mathrm{p}=0.231$, respectively) and attitude ( $\mathrm{p}=0.097, \mathrm{p}=0.166$, respectively). There were significant positive correlations between education and income with knowledge about stroke sign $(\mathrm{r}=0.563, \mathrm{p}=0.009 ; \mathrm{r}=0.489, \mathrm{p}=0.012$, respectively $)$, symptom $(\mathrm{r}=0.322, \mathrm{p}=0.025 ; \mathrm{r}=0.405, \mathrm{p}=0.008$, respectively) and risk factors $(\mathrm{r}=0.736, \mathrm{p}=0.002 ; \mathrm{r}=0.684$, $\mathrm{p}=0.003$, respectively). We also found a positive correlation between age and knowledge $(\mathrm{r}=0.289, \mathrm{p}=0.031)$ as well as the years of education and attitude $(r=0.256, \mathrm{p}=$ $0.038)$.

\section{Discussion}

Identification of the major risk factors of stroke and its clinical presentation has a direct implication for the prevention and rapid intervention for a stroke patient with the possible therapeutic measures. This study shows that the knowledge of and attitude towards stroke risk factors in the general population of Shiraz is adequate. Hypertension was listed as the most common risk factor of stroke followed by smoking. This is consistent with a previous population-based telephone survey in Greater Cincinnati, Ohio, USA [9]. In this study, high blood pressure was the risk factor most frequently identified, and smoking was fourth. Population-based studies in South Korea [15] and Hong Kong [21] also reported that high blood pressure was the most frequently identified risk factor of stroke. In an intensive Australian risk awareness campaign [22], smoking was the most frequently identified risk factor of stroke. Hence, hypertension and smoking remain the most commonly identified risk factors of stroke. A smaller proportion of respondents (4.3-5.1\%) identified diabetes mellitus and heart disease as stroke risk factors. These results suggest that community-based stroke prevention strategies should focus on the established stroke risk factors.

In our study, we found a gap between the lifestyle and knowledge about risk factors. We also observed an incorrect attitude towards stroke in Shiraz: most participants believed that treatment of stroke is difficult and expensive, that the hospitals are not suitable for stroke patients and that neurologists are not available.

In an efficacy study by Stern et al. [23], it was shown that the information on stroke can be successfully increased by using media including television, magazines and newspapers as well as family and friends followed by health professionals and educational campaigns. They 
Table 4. Attitude of respondents related to stroke patients

\begin{tabular}{|c|c|c|c|c|c|}
\hline What is your opinion? & $\begin{array}{l}\text { Completely } \\
\text { agree }\end{array}$ & $\begin{array}{l}\text { Partially } \\
\text { agree }\end{array}$ & No opinion & $\begin{array}{l}\text { Partially } \\
\text { disagree }\end{array}$ & $\begin{array}{l}\text { Completely } \\
\text { disagree }\end{array}$ \\
\hline Stroke patients must be treated by a neurologist & $303(78.7 \%)$ & $71(18.4 \%)$ & $6(1.6 \%)$ & $2(0.5 \%)$ & $3(0.8 \%)$ \\
\hline Stroke patients receive adequate financial support from the government & $17(4.4 \%)$ & $45(11.7 \%)$ & $148(38.4 \%)$ & $112(29.1 \%)$ & $63(16.4 \%)$ \\
\hline Stroke patients receive adequate financial support from insurance companies & $15(3.9 \%)$ & $44(11.4 \%)$ & $160(41.6 \%)$ & $116(30.1 \%)$ & $50(13.0 \%)$ \\
\hline General practitioners are able to prevent stroke & $19(4.9 \%)$ & $76(19.7 \%)$ & $114(29.6 \%)$ & $145(37.7 \%)$ & $31(8.1 \%)$ \\
\hline The stroke patient's medications are cheap & $8(2.1 \%)$ & $7(1.8 \%)$ & $155(40.3 \%)$ & $125(32.4 \%)$ & $90(23.4 \%)$ \\
\hline The neurologists are available & $52(13.5 \%)$ & $131(34.0 \%)$ & $84(21.8 \%)$ & $89(23.2 \%)$ & $29(7.5 \%)$ \\
\hline General practitioners are able to treat stroke & $5(1.3 \%)$ & $15(3.9 \%)$ & $62(16.1 \%)$ & $218(56.6 \%)$ & $85(22.1 \%)$ \\
\hline Physiotherapy of stroke patients is expensive & $94(24.4 \%)$ & $157(40.8 \%)$ & $116(30.1 \%)$ & $16(4.2 \%)$ & $2(0.5 \%)$ \\
\hline Stroke patients should be routinely visited by a psychiatrist or psychologist & $83(21.6 \%)$ & $127(33.0 \%)$ & $60(15.6 \%)$ & $86(22.3 \%)$ & $29(7.5 \%)$ \\
\hline The hospitals are suitable for stroke patients & $16(4.2 \%)$ & $77(20.0 \%)$ & $170(44.2 \%)$ & $101(26.1 \%)$ & $21(5.5 \%)$ \\
\hline Stroke patients will become handicapped in the long term & $14(3.6 \%)$ & $25(6.5 \%)$ & $79(20.5 \%)$ & $199(51.7 \%)$ & $68(17.7 \%)$ \\
\hline Hospital equipments are required for the rest of their lives in stroke patients & $116(30.1 \%)$ & $187(48.6 \%)$ & $59(15.3 \%)$ & $18(4.7 \%)$ & $5(1.3 \%)$ \\
\hline
\end{tabular}

also showed that race or educational level does not affect the increase in knowledge [23] as was confirmed in our study because different ethnic groups including Fars, Bakhtiari and Lor exist in Iran. Other studies also showed that stroke awareness was significantly increased after informative campaigns [24, 25]. Alberts et al. [24] showed that increasing stroke knowledge with means of public and professional education resulted in a reduced time of presentation to the emergency department. All these studies indicate the need for long-term education in order to achieve desirable results.

Knowledge of and attitude towards stroke were significantly associated with age and level of education but not sex and domicile. These were expected findings because - with increasing age and level of education - the level of knowledge increases. These findings are consistent with previous studies [16-22]. Quick recognition of the symptoms would make adequate treatment possible and would minimize the unfavorable effects of stroke. We believe that the use of public media and school education will probably change the level of the population's knowledge of and attitude towards stroke.

\section{Conclusion}

The present study showed a gap between the lifestyle of the population of the city of Shiraz and their knowledge about risk factors as reflected by the necessity of intervention with public and professional educational campaigns and public media in the community.

\section{Appendix: The Questionnaire}

\author{
Age: \\ Sex: Male $\square$ Female $\square$ \\ Location: City $\square \quad$ Village $\square \quad$ Tribes $\square$ \\ Level of education: Illiterate $\square \quad$ Diploma $\square$ \\ Bachelor of Science $\square \quad$ Master of Science $\square \quad$ Doctorate $\square$ \\ Years of education: \\ Type of insurance: \\ Monthly income: $\quad<200$ USD $\square \quad 200-1,000$ USD $\square$ \\ $>1,000$ USD $\square$ \\ Level of knowledge: I myself have had stroke $\square$ \\ My first-degree relatives have had stroke $\square$ \\ None mentioned $\square \quad$ First-degree relative of my family \\ has stroke $\square$
}

Participants were asked to answer the following questions:

(1) High blood pressure is a risk factor for stroke

(2) Only high maximum blood pressure (systole) is a risk factor for stroke

(3) Only high minimum blood pressure (diastole) is a risk factor for stroke

(4) Stroke can be prevented by reducing blood pressure

(5) Cardiac rhythm irregularities (arrhythmias) are among the causes of stroke

(6) Exercising is among the causes of stroke

(7) Obesity is among the causes of stroke

(8) People who do not smoke are more susceptible to develop stroke

(9) People with high plasma cholesterol are more susceptible to develop stroke

(10) A patient with stroke will never be cured completely

(11) Stroke causes generalized body pain

(12) Patients with stroke should be treated by a neurologist

(13) Paresthesia of one leg and one arm is among the symptoms of stroke

(14) Diabetes mellitus is a risk factor for stroke

(15) Paresthesia of limbs is among the symptoms of stroke

(16) The government allocates enough of its budget to stroke patients

(17) A stroke patient does not need physiotherapy

(18) Stroke patients should immediately be transferred to a hospital

(19) Stroke patients must undergo brain surgery

(20) One-sided paralysis of the body is a sign of stroke

(21) Depression is a complication of stroke 
(22) Insurance companies allocate enough of their budget to stroke patients

(23) One-sided paresthesia of the body is a symptom of stroke

(24) Stroke patients should immediately be transferred to a neurology clinic

(25) Chest pain is among the symptoms of stroke

(26) Bed sore is a complication of stroke

(27) Stroke patients' medications are cheap

(28) Urinary and fecal incontinence is a complication of stroke

(29) Stroke patients cannot return to the community

(30) Neurologists are available

(31) All strokes are caused by cardiac embolism

(32) General practitioners are able to prevent or treat stroke

(33) An ambulance is not needed for the transfer of stroke patients

(34) All strokes are caused by rupture of brain vessels

(35) Controlled diet in elderly individuals can prevent stroke

(36) Positive family history of stroke is a risk factor for stroke

(37) People with high plasma triglycerides are more susceptible to develop stroke

(38) A general practitioner can treat a stroke patient

(39) Stroke can be prevented by controlling blood pressure

(40) All the stroke patients become completely paralyzed or pass away

(41) Sometimes stroke happens following a myocardial infarction

(42) Abdominal discomfort (dyspepsia) is a symptom of stroke
(43) Stroke can be prevented by controlling blood glucose levels in those with diabetes mellitus

(44) Physiotherapy in stroke patients is expensive

(45) Some stroke patients will need angiography and stent placement

(46) Some stroke patients will need brain surgery

(47) Stroke patients on warfarin need routine blood tests

(48) Dysarthria is a sign of stroke

(49) Severe vertigo is a symptom of stroke

(50) Diplopia is a symptom of stroke

(51) Ataxia is a sign of stroke

(52) Stroke patients should be visited by a psychiatrist

(53) Stroke is caused by stress

(54) Hospitals are equipped enough to take care of stroke patients

(55) Stroke cannot be prevented

(56) Stroke cannot be treated

(57) Stroke only happens in elderly individuals

(58) Stroke can be treated in the first month after stroke only

(59) Blood pressure should be reduced immediately in stroke patients

(60) Cold sweating is a sign of stroke

(61) Dyspnea is a symptom of stroke

(62) All stroke patients are considered handicapped

(63) Stroke patients should be admitted to the intensive care unit

\section{References}

1 Smith WS, English JD, Johnston SC: Cerebrovascular diseases; in Fauci AS, Braunwald E, Kasper DL, Hauser SL, Longo DL, Jameson JL, Loscalzo J (eds): Harrison's Principles of Internal Medicine. New York, McGraw-Hill, 2008, pp 2513-2536.

$>2$ Davis S, Lees K, Donnan G: Treating the acute stroke patient as an emergency: current practices and future opportunities. J Clin Pract 2006;60:399-407.

$\checkmark 3$ Murray CJ, Lopez AD: Mortality by cause for eight regions of the world: Global Burden of Disease Study. Lancet 1997;349:1269-1276.

$\checkmark 4$ Bronner LL, Kanter DS, Manson JE: Primary prevention of stroke. N Engl J Med 1995;333: 1392-1400.

$>5$ Inzitari D, Eliasziw M, Gates P, Sharpe BL, Chan RKT: The causes and risk of stroke in patients with asymptomatic internal-carotid-artery stenosis. N Engl J Med 2000;342: 1693-1700.

$\checkmark 6$ Bushnell CD, Goldstain LB: Physician knowledge and practices in the evaluation of coagulopathies in stroke patients. Stroke 2002;33:948-953.

$\checkmark 7$ Williams LS, Bruno A, Rouch D, Marriott DJ: Stroke patients' knowledge of stroke: influence on time to presentation. Stroke 1997; 28:912-915.

$>8$ National Institute of Neurological Disorders and Stroke Recombinant Tissue Plasminogen Activator Study Group: TPA for acute ischemic stroke. N Engl J Med 1995;333: 1581-1587.
19 Pancioli AM, Broderick J, Kothari R, Brott T, Tuchfarber A, Miller R, Khoury J, Jauch E: Public perception of stroke warning signs and knowledge of potential risk factors. JAMA 1998;279:1288-1292.

10 Deng YZ, Reeves MJ, Jacobs BS, Birbeck GL, Kothari RU, Hickenbottom SL, Mullard AJ, Wehner S, Maddox K, Majid A, Paul Coverdell National Acute Stroke Registry Michigan Prototype Investigators: IV tissue plasminogen activator use in acute stroke: experience from a statewide registry. Neurology 2006;66:306-312

11 Becker K, Fruin M, Gooding T, Tirschwell D, Love P, Mankowski T: Community-based education improves stroke knowledge. Cerebrovasc Dis 2001;11:34-43.

12 Rowe AK, Frankel MR, Sanders KA: Stroke awareness among Georgia adults: epidemiology and considerations regarding measurement. South Med J 2001;94:613-618.

13 Hux K, Rogers T, Mongar K: Common perceptions about strokes. J Community Health 2000;25:47-65.

14 Sug Yoon S, Heller RF, Levi C, Wiggers J, Fitzgerald PE: Knowledge of stroke risk factors, warning symptoms and treatment among an Australian urban population. Stroke 2001;32:1926-1930.

15 Kim JS, Yoon SS: Perspectives of stroke in persons living in Seoul, South Korea: a survey of 1,000 subjects. Stroke 1997;28:11651169.

16 Ramsden VR, Shuaib A, Reeder BA, Khan K, Liu L: Risk factor awareness: a randomized telephone survey of public knowledge. Can J Public Health 1994;85(suppl 2):57-60.
17 Campos-Sousa RN, Soares VY, Almeida KJ, Carvalho LI, Jacobina KS, Athayde Netto AE, Macêdo Ede A, Veloso LA: Knowledge of stroke among a Brazilian urban population. Arq Neuropsiquiatr 2007;65:587-591.

18 Al Shafaee MA, Ganguly SS, Al Asmi AR: Perception of stroke and knowledge of potential risk factors among Omani patients at increased risk for stroke. BMC Neurol 2006; 6:38.

19 Pandian JD, Jaison A, Deepak SS, Kalra G, Shamsher S, Lincoln DJ, Abraham G: Public awareness of warning symptoms, risk factors, and treatment of stroke in northwest India. Stroke 2005;36:644-648.

20 Evci ED, Memis S, Ergin F, Beser E: A population-based study on awareness of stroke in Turkey. Eur J Neurol 2007;14:517-522.

-21 Cheung RTF, Li LSW, Mak W, Tsang KL, Lauder LJ, Chan KH, Fong CY: Knowledge of stroke in Hong Kong Chinese. Cerebrovasc Dis 1999;9:119-123.

22 Commonwealth of Australia: The National Tobacco Campaign. www.quitnow.info.com (accessed December 16, 1999).

23 Stern EB, Berman M, Thomas JJ, Klassen AC: Community education for stroke awareness: an efficacy study. Stroke 1999;30:720-723.

24 Alberts MJ, Perry A, Dawson DV, Bertels C: Effects of public and professional education on reducing the delay in presentation and referral of stroke patients. Stroke 1992;23:352356.

25 Silver FL, Rubini F, Black D, Hodgson CS: Advertising strategies to increase public knowledge of the warning signs of stroke. Stroke 2003;34:1965-1969. 